\title{
Two dimensional finite element modelling of floodplain flow
}

\author{
Modélisation à deux dimensions par éléments finis d'un écoulement \\ en plaine alluviale
}

\author{
by P.D. Bates and C.A.M.E. Wilson \\ Research Centre for Environmental and Geophysical Flows, School of Geographical Sciences, \\ University of Bristol
}

\section{J.-M. Hervouet}

Laboratoire National d'Hydraulique, EDF Direction des Etudes et Recherches

M.D. Stewart

Engineer, Babtie Group Ltd, UK.

Cet article s'intéresse à la simulation numérique d'écoulements à surface libre à l'échelle de la rivière. Une prédiction précise de tels écoulements serait une avancée majeure à la fois pour l'ingénierie hydraulique et l'occupation des sols. Jusqu'à maintenant, cet objectif a été difficile à atteindre en raison de la complexité du modèle et du manque de données de validation distinctes des données de calibration. La méthode de validation présentée ici a été developpée pour respecter cette contrainte. En effet, les résultats issus d'un modèle $2 D$ par éléments finis. TELE$M A C-2 D$ développé par le $L N H$, sont comparés à la fois aux résultats d'un modèle et à des données de terrain, ce qui permet d'effectuer calibration et validation indépendemment.

\section{INTRODUCTION}

Recent work has illustrated the potential of two dimensional finite element codes for modelling flow in meandering compound channels $[1,2,3,4,5]$. Such models have been shown to offer a number of advantages over alternative one $[6,7]$ and two $[8]$ dimensional finite difference schemes due to their ability to represent complex topography with a minimum number of computational nodes and the potential accuracy of the finite element method [9].

Whilst the potential utility of this class of scheme for river flow applications is clear, insufficient model validation remains a major constraint on the development of practical engineering tools. In particular, current studies largely compare model predictions to real observations on the basis of bulk flows (discharges) at the reach downstream boundary (see for example [2]). This result is typically achieved through calibration of the model friction parameters to replicate this downstream hydrograph and, as a consequence, the calibration and validation phases are not independent. Given the number of degrees of freedom present in such calibration, whereby separate friction parameters can be assigned at each computational node and at each time step, a reasonable correspondence between observed reach outflow data and a calibrated flood routing model (of any dimensionality or spatial resolution) is relatively easy to accomplish. Moreover, there is a strong element of equifinality in this calibration procedure as many different parameterization sets may produce equally acceptable fits to a given set of observed data. The quality of this type of evidence as proof that the model is a robust predictive tool is therefore questionable, and in using such data it has proved impossible to disaggregate error due to model parameterization, structural or discretization errors, data errors or flaws in the calibration procedure itself.

Similar validation problems exist with more traditional, one dimensional approaches to flood routing, however the recent move towards two dimensional simulations renders the situation much more acute. Flood routing requires a limited number of prediction products from numerical models. However, for an increasing number of applications, in particular sediment transport and pollution studies, the spatially distributed velocity and water depth fields predicted by two dimensional models are of direct relevance. From the above discussion it is clear that much further validation evidence is required if any confidence is to be placed in the distributed flow field predictions which two dimensional models also generate. A need therefore exists to conduct model validation against high quality data which is independent of any friction calibration procedure undertaken. Such data has 
(a)

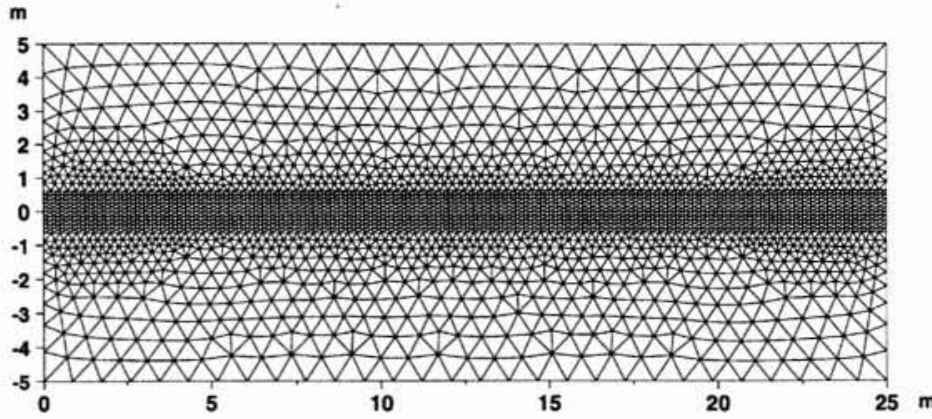

(b)

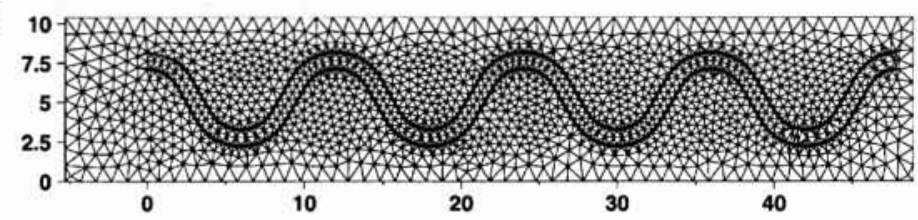

(c)

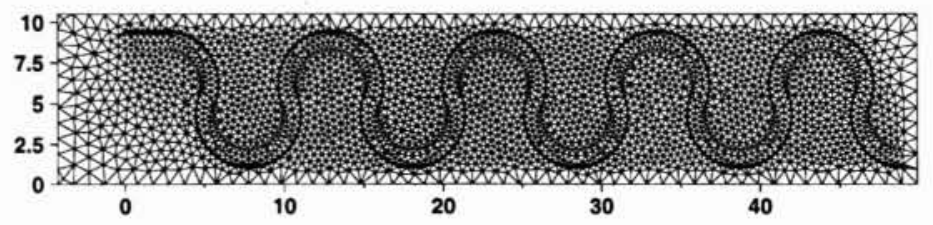

(d) $\mathrm{m}$

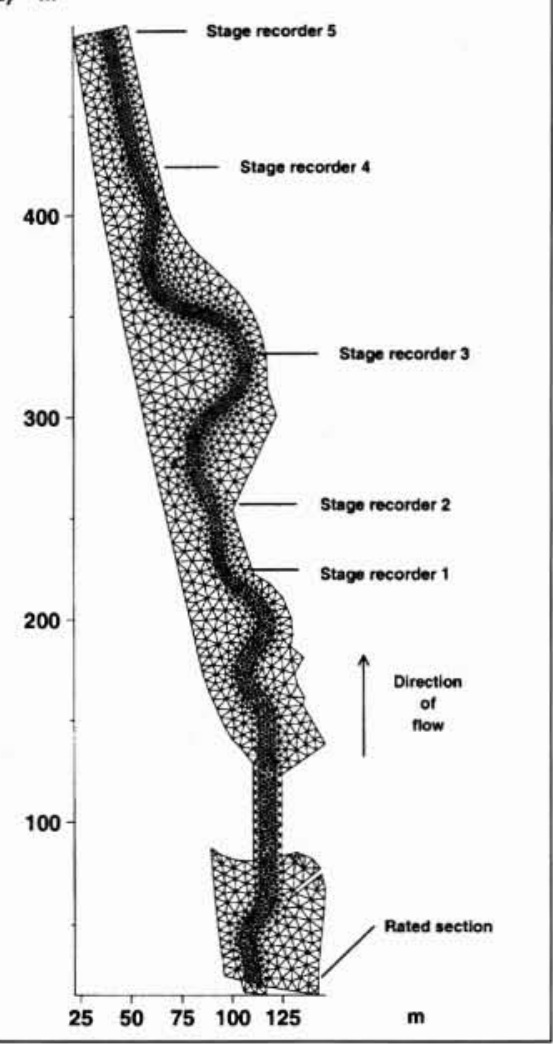

1. Finite element mesh discretizations developed for the: (a) Flood Channel Facility Phase A1 channel; (b) the FCF Phase B21 channel; (c) the FCF Phase B39 channel and (d) a $500 \mathrm{~m}$ reach of the River Blackwater in Hampshire instrumented by the UK Environment Agency with a rated section at the upstream inflow and 5 stage recorders, of which 1-4 are internal to the model domain.

recently become available through a number of developments in large scale physical modelling $[10]$ and high resolution field data capture [11] which now afford the unique possibility of meeting this research need. Accordingly, we here compare a finite element solution of the Shallow Water equations to data from the EPSRC large scale Flood Channel Facility (FCF) physical model and to highly detailed field data from the River Blackwater in the UK.

\section{RESEARCH DESIGN}

The Flood Channel Facility provides a river model building space $50 \mathrm{~m} \times 10 \mathrm{~m}$ with a maximum available discharge of $1 \mathrm{~m}^{3} \mathrm{~s}^{-1}$. The significance of work carried out since 1987 in the FCF is that carefully collected, high quality data has been obtained for two-stage channel flow at a large scale. Finite element meshes were configured on an identical scale (see Figure la, b and c) to the physical model and the results compared in terms of the ability to replicate measured stage-discharge rating curves at a point internal to the model domain for three channel configurations: straight channel (Series A1), $60^{\circ}$ channel (Series B21) and $110^{\circ}$ channel (Series B39).

For the River Blackwater a $500 \mathrm{~m}$ reach has been instrumented with 5 water level recorders by the UK Environment Agency, thereby providing a unique level of data availability. Here the finite element mesh (see Figure 1d) was constructed to represent the reach using topographic data from field survey taken every $20 \mathrm{~m}$ and was used to analyse the ability of a two dimensional flow field approximation to replicate transient water levels along the reach during dynamic flood events. Model tests against these unique data sources allow, for the first time, the ability to overcome current validation and calibration constraints and allow an agenda for future model development to be more rigorously defined.

\section{MODEL DESCRIPTION}

The two dimensional finite element model TELEMAC-2D $[12,13]$ was selected as the basis for the numerical simulations reported in this paper. This generalised code has recently been extended to consider river channel/floodplain applications $[14]$ by the incorporation of two specific developments. Firstly, a Streamline Upwind/Petrov Galerkin (SUPG) solver [15] was implemented to ensure mass conservation and an oscillation free solution without excessive mesh refinement or the addition of artificial diffusion. This enabled complex reach scale floodplain topographies to be represented in a computationally efficient manner. Secondly, an algorithm was incorporated to account for the influence of partially wet elements on the solution (see [16]). The original model has undergone considerable validation against both analytical solutions and a range of fluvial flow problems $[16]$ and the enhanced TELEMAC-2D code has been compared $[18]$ to the generalised two dimensional finite element scheme RMA-2 [19] in terms of their ability to simulate a small flood event over an $11 \mathrm{~km}$ reach of the River Culm, Devon, UK. For this test case the TELEMAC-2D code was shown to have significant advantages over the alternative method in terms of bulk flow prediction and its ability to simulate a wider range of inundation states. 
The TELEMAC-2D code solves the second order partial differential equations for depth averaged fluid flow (the Shallow Water equations) derived from the full three dimensional Navier-Stokes equations. This gives a system consisting of an equation for mass continuity and two force-momentum equations. These are given in non-conservative form as :

$$
\begin{aligned}
& \frac{\partial h}{\partial t}+\vec{u} \cdot \overrightarrow{\operatorname{grad}}(h)+h \operatorname{div} \overrightarrow{(u)}=0 \\
& \frac{\partial u}{\partial t}+\vec{u} \cdot \overrightarrow{\operatorname{grad}}(u)+g \frac{\partial h}{\partial x}-\frac{1}{h} \operatorname{div}(v h \overrightarrow{\operatorname{grad}}(u))=S_{x}-g \frac{\partial Z_{f}}{\partial x} \\
& \frac{\partial v}{\partial t}+\vec{u} \cdot \overrightarrow{\operatorname{grad}}(v)+g \frac{\partial h}{\partial y}-\frac{1}{h} \operatorname{div}(v h \overrightarrow{\operatorname{grad}}(v))=S_{y}-g \frac{\partial Z_{f}}{\partial y}
\end{aligned}
$$

Where : $u, v$ are the velocity components in the $x$ and $y$ cartesian directions; $h$ is the depth of flow; $Z f$ is the bed elevation; $\mathrm{n}$ is the turbulent eddy viscosity; $S_{x} S_{y}$ are the source terms; $g$ is the gravitational acceleration and $t$ is the time.

The model employs either constant eddy viscosity, mixing length or $k-\varepsilon$ turbulence closure schemes, although the former was used to develop all the simulations reported in this paper. This approach was taken both to minimise computational cost and because for preliminary simulations information may not, as in this case, be available to justify the $a$ priori selection of a more complex scheme. Boundary friction is represented by a standard quadratic power law and parameterized in terms of the Manning coefficient. The system is solved for a continuum of linear triangular finite elements using an implicit fractional step method [20] where advection terms are solved initially separate from propagation, diffusion and source terms which are solved together in a second step.

\section{IV — NUMERICAL SIMULATIONS}

For the River Blackwater model a single dynamic flood event which took place on $8^{\text {th }}$ of January, 1996 was simulated. Boundary conditions consisted of an imposed flow rate at the upstream inflow and an imposed water surface elevation at the downstream outflow. This combination gives a well posed problem according to the theory of Characteristics providing that there is no recirculation at the downstream outflow.

Initial conditions for the dynamic simulation were assumed to be steady state flow at bankful discharge calculated using identical friction parameters to those employed in the dynamic simulation. To obtain this, a simulation was undertaken for each site commencing with an identical water depth at each node. Non-dynamic boundary conditions representing bankful discharge were then imposed and a simulation made which proceeded simulated until any waves created by the start-up procedure had passed out of the domain. This led to flow contained in the channel only with floodplain areas fully dry.

Preliminary dynamic simulations were undertaken to determine appropriate floodplain and channel friction coefficients for this event. Although, even though internal gauge data existed, calibration was only undertaken against observed flow data at the catchment downstream outflow. At this location on each model three possible calibration data sets existed: water levels, discharges and information on timing of peak flows. Of these, water level is used as a model boundary condition and discharge is subject to the additional uncertainties due to the rating equation transformation. As a consequence only the timing of peak flow is accurately known and independent of the model predictions. Calibration was therefore achieved by manipulating friction parameters solely to minimise the phase error between predicted and observed peak discharge at the reach outflow. This has the advantage of being a relatively robust test of the model as all other aspects of the hydrograph (volume, magnitude of peak, timing and speed of rise, timing and attenuation of recession) were allowed to vary freely. Moreover, data from internal gauging stations were thus fully independent of the calibration procedure. As a result of this process Mannings $n$ friction coefficient values of 0.029 for the channel and 0.05 for the floodplain were chosen.

In the case of the physical model tests boundary conditions, topography and friction values (see Table 1) were known from the experimental configuration (see [21]). The finite element model was therefore constructed with exactly these data and calibration was thus unnecessary. Any remaining discrepancy between the model predictions and the experimental data could therefore be assumed to be due to inadequacies with the two dimensional flow field assumption, the turbulence closure sub-model, the wetting and drying scheme or as a result of the numerical approximation scheme used.

Boundary conditions for the FCF tests were therefore identical to those used for the Blackwater simulations, howe-

\begin{tabular}{|l|l|l|l|}
\hline Criteria & Phase A1 & Phase B21 & Phase B39 \\
\hline Total width $(\mathrm{m})$ & 10 & 10 & 10 \\
\hline Channel base width $(\mathrm{m})$ & 1.5 & 0.9 & 0.9 \\
\hline In-channel depth & 0.15 & 0.15 & 0.15 \\
\hline Side slopes & $1: 1$ & $1: 1$ & $1: 1$ \\
\hline Channel top width $(\mathrm{m})$ & 1.8 & 1.2 & 1.2 \\
\hline Floodplain width $(\mathrm{m})$ & 4.1 & variable & variable \\
\hline Sinuosity & straight & 1.374 & 2.034 \\
\hline Inflow condition & Discharge & Discharge & Discharge \\
\hline Outflow condition & Fixed stage & Fixed stage & Fixed stage \\
\hline Skin friction (Mannings $\mathrm{n})$ & 0.01 & 0.01 & 0.01 \\
\hline
\end{tabular}

Table 1: Experimental configuration for Flood Channel Facility experiments AI, B2I and B39 (after [21]). These data were used to configure the finite element models shown in Figures $1 a, b$ and $c$. 


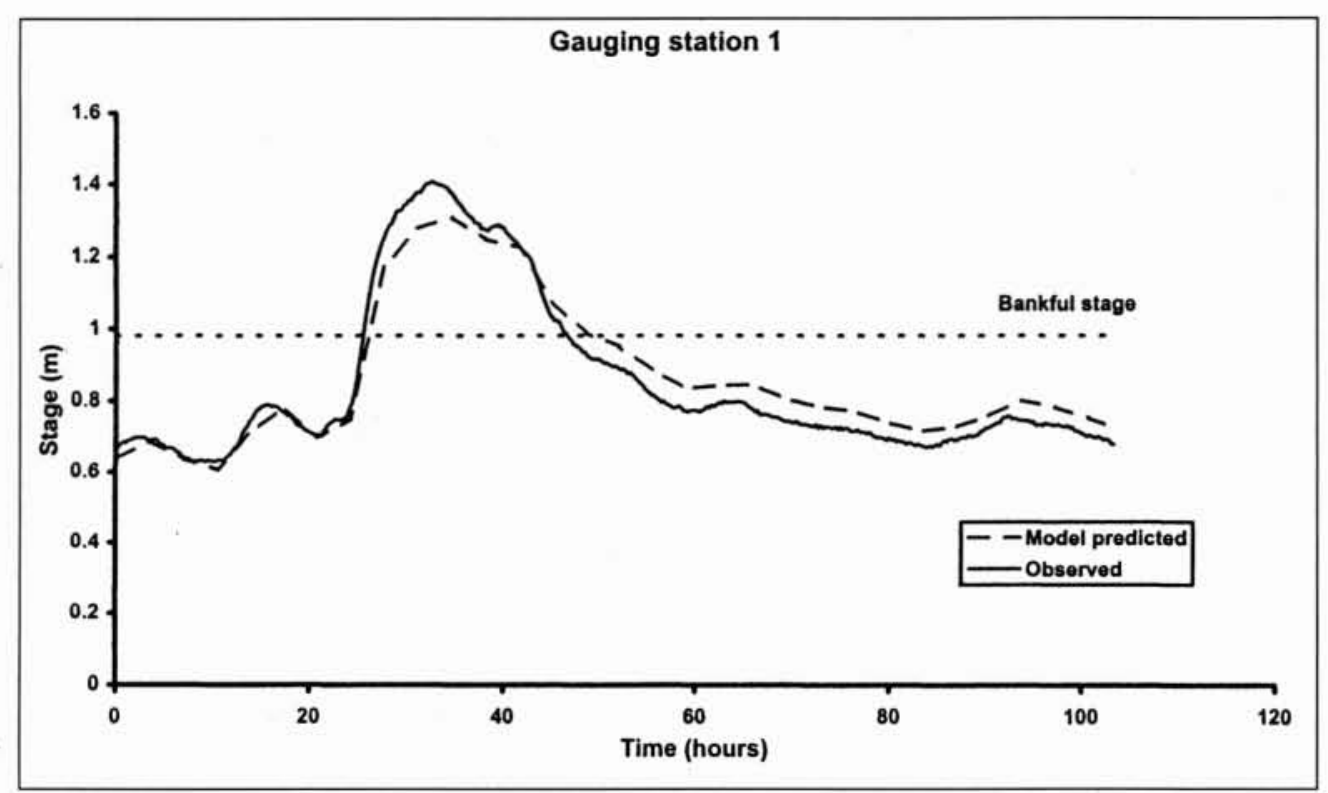

2a-d: Comparison of the four observed River Blackwater stage hydrographs available at locations internal to the model computational domain to predictions from a two dimensional finite element model. Note bankful stage is at $0.75 \mathrm{~m}$ at each gauging station.
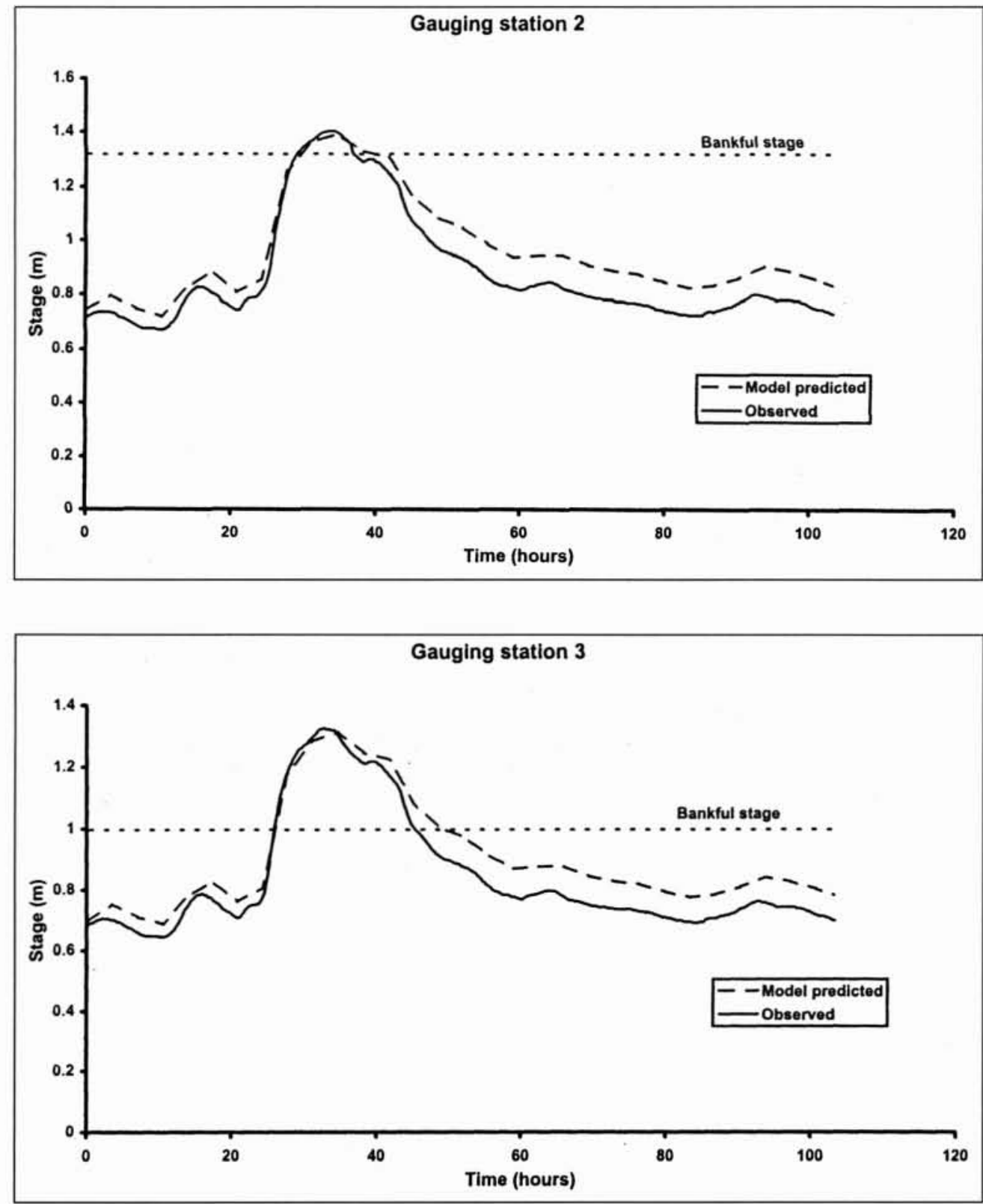


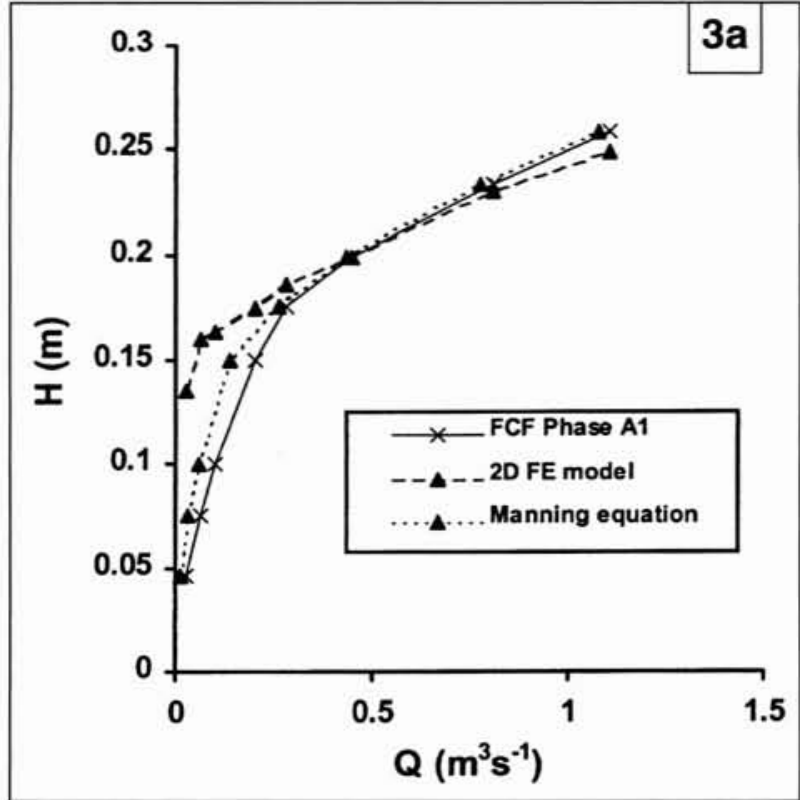

3a-c. Comparison of observed stage-discharge rating curves for the three Flood Channel Facility configurations with predictions from the TELEMAC-2D two dimensional finite element model and the Manning equation.
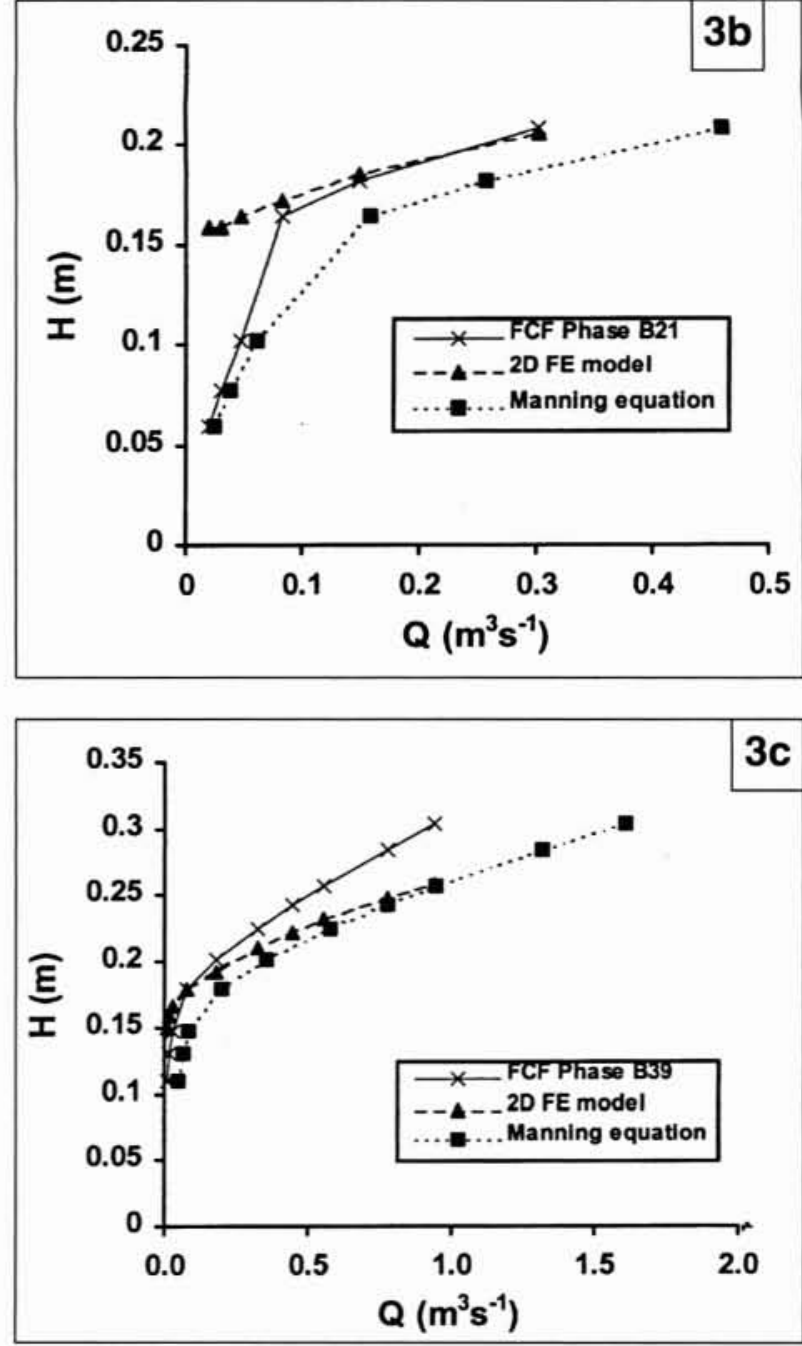

appeared to be no consistent bias within the model to under or over-prediction. Consideration of the full stage hydrographs showed a more complete picture of the model internal behaviour. At gauging stations 1, 2 and 3 there was a very good match between observed and predicted stage, particularly around the hydrograph peak. However, the model over-predicted stage by a maximum of $0.1 \mathrm{~m}$ during the recession limb of the hydrograph. Moreover, it was clear that the divergence between model predictions and the field observations occured progressively below bankful discharge. The discrepancy between model and observations is most marked at gauging station 4 with an apparent systematic offset of $0.1-0.13 \mathrm{~m}$ between the two data sets. While a model error is possible, the consistency of this offset throughout the hydrograph may imply an error in the datum level of the gauge determined from field survey or the elevation of the base of channel used in the model.

Further analysis of model performance, particularly for inchannel flows, can be accomplished with the Flood Channel Facility stage-discharge rating curve data. Although this is a simple bulk hydraulic measure, the FCF data is highly accurate. Moreover, as many of the typical uncertainties present during model construction (friction, topography, boundary conditions) can be controlled for and the data set spans the 
transition from in-channel to out-of-bank flows it provides a critical test for the model TELEMAC-2D. Results from the two dimensional finite element model simulations are compared to those from the physical model in Figure 3a-c. In addition, an analytical stage-discharge curve calculated using the single channel method in conjunction with the Manning equation is shown for comparison. The single channel method was applied with Mannings $n$ equal to 0.01 throughout the cross section. This roughness coefficient was calibrated through flume tests reported in Ackers $[22 \mid$ and reflects the energy losses due to the boundary friction only. It therefore did not take into account any additional " roughness " generated by channel meandering. Whilst standard practice is to increase $n$ to account for the effect of channel meandering and channel/floodplain momentum exchange using some empirical method (see for example Chow, 1959), in these initial simulations we additionally wished to determine the extent to which such energy losses could be explicitly modelled using a two dimensional scheme. We therefore required a " control " stage-discharge curve to demonstrate the magnitude of such effects. For the straight channel case (FCF Phase Al) these results show that the Manning equation and the two dimensional finite element calculation produce a good match to the observed data for out-of-bank flows ( $>0.15 \mathrm{~m}$ ). For in-channel flows, however, the single channel method provides a better match. In this situation it is again clear that the numerical model cannot easily represent conditions of less than bankful discharge. This can also be observed in the Phase B21 and B39 calculations and is consistent with the simulations made with the River Blackwater model.

While the Manning equation provides a good match to the straight channel data, it fails to accurately represent both meandering channel configurations when flow is out-ofbank. Indeed, this match becomes progressively worse as the sinuosity increases from $60^{\circ}$ (FCF Phase B21) to $110^{\circ}$ (FCF Phase B39). The two dimensional finite element model, however, provides an excellent match in both cases.

\section{DISCUSSION}

The simulation results described above clearly show that for flood flows in compound channel flow problems simulated at this mesh resolution a two dimensional finite element model with simple turbulence closure is able to accurately predict hydraulic measures such as discharge, stage and inundation extent at internal cross sections. This demonstrates that even with a relatively crude two dimensional spatial and dimensional discretisation of the lateral velocity gradient in the near channel region the TELEMAC-2D model is able to represent the momentum transfer between main-channel and floodplain flows sufficiently well to replicate typical physical model and distributed field data on stage and discharge. This momentum transfer process has been shown to be critical to the development of flood flows in compound channels [23] and it has been suggested that its complexity invalidates models which employ a one dimensional representation for out-of-bank conditions [24]. Effectively, a two dimensional depth averaged model is the simplest scheme that can explicitly represent this process and this study has demonstrated that such a description captures many of its essential attributes. Moreover, the model is also able to accurately represent the additional energy losses which occur due to channel meandering (see for example [10]). These largely comprise the vigorous mixing of channel and floodplain water across meander loops. Here channel water spills onto the floodplain from the downstream apex of meander bends before flowing across the meander loop and rejoining the main channel flow at the next meander. This is a complex process and may be at least as important as main-channel/floodplain momentum exchange.

By comparison the single channel method as applied cannot take into account these energy losses in meandering channels and natural geometries without an empirical correction. In the case of the $110^{\circ}$ channel (FCF Phase B39) this failure leads to an under-prediction of stage by the single channel method of up to $20 \%$. This is not surprising given the nature of the single channel method $[25]$ whereby the energy losses are represented solely by a lumped coefficient. As the published roughness coefficient for the FCF is solely a description of the surface roughness and does not include any additional form energy loss mechanisms it is clear that meandering channel effects energy are highly significant during flood flow conditions.

The two dimensional finite element model does however fail to adequately replicate in-bank flows, although it does appear to correctly simulate the onset of flooding (see for example data point 4 on Figure $2 b$ ). This is perhaps unsurprising as the mesh discretization was originally designed to simulate inundation in response to large out-of-bank flood events. However, it is instructive to consider the precise reasons for this inability to simulate in-channel processes inability. While the River Blackwater simulations indicate the scope of the problem, the uncertainties involved in model construction mean that it is impossible to determine whether topographic error, poor optimisation of the boundary friction calibration, flow measurements error or the model assumptions themselves are at fault. The Flood Channel Facility simulations allow all but the latter to be eliminated as explanations as topography, friction and flow can be rigorously controlled for. Clearly, some aspects of the two dimensional model structure are not appropriate for the representation of an in-bank flow when that channel is set within a wider floodplain belt. This is unusual as we have already demonstrated that the model is capable of simulating the much more complex out-of-bank case. Indeed, standard hydraulic practice for in-channel flows makes use of a one-dimensional flow field assumption [24]. It therefore seems unlikely that the model process representation (dimensionality, turbulence closure, friction) is at fault. We have been able to demonstrate that the model can represent complex out-of-bank flows. Thus, for the simpler in-channel case a two dimensional flow model with simple turbulence would appear to be sufficient, particularly when the standard hydraulic approach to this problem is a one-dimensional model [24]. A better explanation would therefore appear to be the presence of very steep elements representing the channel banks which become partially dry at less than bankful flow. These do not appear to be well represented by the Shallow Water equations, which typically only apply to regions with topographic gradients of less than $10 \%$. Additionally these elements may cause problems with the TELEMAC-2D wetting and drying algorithm which was designed solely for shallow gradient elements on floodplains and tidal flats. Clearly further work is needed to confirm this view and test competing hypotheses regarding the poor performance for in-channel flows. 


\section{VI $\square$ CONCLUSIONS}

This paper has attempted to overcome a number of limitations inherent in typical calibration and validation procedures used in hydraulic modelling. In particular, the consequences of using non-independent calibration and validation data sets for floodplain flow simulations were explored. Such procedures were developed for the previous generation of one dimensional hydraulic schemes and, while broadly adequate for flood routing studies, are unsuitable for recently developed two and three dimensional models. Such schemes were shown to require a much more detailed and careful approach to the validation issue in order to increase confidence in their use for practical engineering problems. In this context, recently available high quality data sets, one from a large scale physical model and one from a heavily instrumented field site were used to validate the two dimensional finite element model, TELEMAC-2D. The ability to ensure independence of calibration and validation leads to a number of insights into model performance that would not hitherto have been possible. In particular we were able to isolate a need to conduct further research into the representation of wetting and drying processes in regions of relatively high lateral slope on the channel banks. Previously this aspect of the model performance could not have been disaggregated from calibration effects. Whilst much further validation of this type is necessary for the development of a robust predictive tool it is clear that the approach to model validation outlined in this paper is worthy of significant future investigation

\section{ACKNOWLEDGEMENTS}

The authors wish to gratefully acknowledge the support of David Van Beesten of the UK Environment Agency for donation of flow and topography data for the River Blackwater study site. Catherine Wilson was supported by EPSRC Grant GR/L 95694. Mike Stewart was supported by NERC Grant GR3/09925.

\section{REFERENCES}

[1] Samuels P.G. (1985). “ Modelling of river and flood plain flow using the finite element method ". Hydraulics Research Ltd., Technical Report SR61, Wallingford.

[2] Gee, D.M., Anderson, M.G. and Baird, L. (1990). " Large scale floodplain modelling " Earth Surface Processes and Landforms, 15,512-523

[3] Bates, P.D., Anderson, M.G., Baird, L., Walling, D.E. and Simm, D. (1992). " Modelling floodplain flow with a two dimensional finite element scheme ". Earth Surface Processes and Landforms, 17. 575-588.

[4] Feldhaus , R., Höttges, J., Brockhaus, T. and Rouvé, G. (1992). "Finite element simulation of flow and pollution transport applied to a part of the River Rhine ". In: Falconer, R.A., Shiono, K. and Matthews, R.G.S (Eds.), Hydraulic and environmental Modelling; Estuarine and River Waters, Ashgate Publishing, Aldershot, 323-344.

[5] Anderson, M.G. and Bates, P.D. (1994). "Initial testing of a two dimensional finite element model for floodplain inundation ". Proceedings of the Royal Society of London. Series A. 444, 149-159.

[6] Cunge, J.A., Holly, F.M. and Verwey, A., (1980). Practical aspects of computational river hydraulics. Pitman, London.
[7] Fread D.L.. (1985). Channel routing. In M.G. Anderson and T.P. Burt (eds), Hydrological forecasting, John Wiley and Sons. Chichester, 437503 .

[8] Zeike W. and Urban W., (1981). Two dimensional modelling of rivers with flood plains. In Numerical Modelling of River Channel and Overland Flow for Water Resources and Environmental Applications, IAHR Publication, Delft, The Netherlands..

[9] Huyakorn, P.S, and Pinder, G.F., (1983). Computational methods in subsurface flow. Academic Press, New York, USA.

[10] Sellin, R.H.J. and Willetts, B.B. (1996). “ Three Dimensional structures, memory and energy dissipation in meandering compound Channe Flow ". In Anderson, M.G., Walling, D.E. and Bates, P.D. (Eds.), Floodplain Processes, John Wiley and Sons. Chichester, 255-289.

[11] Naish, C. and Sellin, R.H.J., (1995). Scaling and hydraulic modelling for small and large scale river flows. 25th IAHR Congress HYDRA 200. London, UK, Volume 1, 111-116.

[12] Hervouet J-M. (1989). * Comparison of experimental data and laser measurements with the computational results of TELEMAC-2D code (shallow water equations) ". In:. Maksimovic, C. and Radojkovic, M. (Eds), Computational and experimental methods in hydraulics (HYDROCOMP ë9), eds., Elsevier, Amsterdam. 237-242.

[13] Hervouet. J-M. (1993). " Validating the numerical simulations of dam-break and floods". Advances in Hydroscience and Engineering Vol 1 Part A. Washington, USA, 754-761.

[14] Bates, P.D., Hervouet, J.-M and Anderson, M.G. (1994). “ Computation of a flood event using a two dimensional finite element model and its comparison to field data ". In P. Molinaro and L. Natale (Eds), " Model. ling of Flood Propagation over Initially Dry Areas ", American Society of Civil Engineers, New York. 243-256.

[15] Brookes, A.N. and Hughes, T.J.R., 1982. " Streamline Upwind/Petrov Galerkin formulations for convection dominated flows with particular emphasis on the incompressible Navier-Stokes equations " Computer Methods in Applied Mechanics and Engineering, 32. 199-259.

[16] Hervouet, J.-M. and Janin, J.-M., (1994). " Finite element algorithms for modelling flood propagation ". In P. Molinaro and L. Natale (eds), Modelling flood propagation over initially dry areas. American Society of Civil Engineers, New York, 102-113.

[17] Hervouet, J-M. and Van Haren. L. (1996). " Recent Advances in Numerical Methods for Fluid flow". In Anderson, M.G., Walling. D.F and Bates, P.D (Eds.), Floodplain Processes, John Wiley and Sons, Chichester, 183-214

[18] Bates, P.D., Anderson, M.G. and Hervouet, J.-M. (1995). " An initial comparison of two 2-dimensional finite element codes for river flood simulation" Proc. Instn. Civ. Engrs., Wat., Marit. and Energy, 112, 238-248.

[19] King, I.P. and Norton, W.R., (1978). “ Recent applications of RMA's finite element models for two dimensional hydrodynamics and water quality ". In C.A. Brebbia, W.G. Gray and G.F. Pinder (eds), “" Proceedings of the Second International Conference on Finite Elements in Water Resources". Pentech Press, London, 81-99.

[20] Marchuk, G.I., (1975). " Methods of numerical mathematics " Springer-Verlag, New York, 316pp.

[21] Harpin, R., Webb, D.R., Whitlaw, C.D., Samuels, P.G. and Wark, J.B. (1995). Benchmarking of hydraulic models. Stage 1 Final Report to the UK National Rivers Authority, Research and Development Project 508. National Rivers Authority. UK, 39pp.

[22] Ackers, P., (1989). Resistance functions for the Wallingford facility. SERC Flood Channel Research Design Manual Technical Report, Volume 1.

[23] Ervine, D.A. and Baird, J.I., (1992). Rating curves for rivers with overbank flow. Proceedings of the Institution of Civil Engineers, Part 2, 73, $465-472$.

[24] Knight, D.W. and Shiono, K. (1996). 'River Channel and Floodplain Hydraulics.' In Anderson, M.G., Walling, D.E. and Bates, P.D. (Eds.), Floodplain Processes, John Wiley and Sons, Chichester, 139-182.

[25] Myers, W.R.C., (1987). Velocity and discharge in compound channels. ASCE Journal of Hydraulic Engineering. 113, 753-766. 